\title{
PLATAFORMA DIGITAL «LUDOTECA JURÍDICA»: UNA APUESTA POR LA "GAMIFICACIÓN» EN DERECHO
}

Digital platform «ludoteca jurídica»: a bet for the gamification in law

Recibido: 30 de noviembre de 2019

Aceptado: 16 de diciembre de 2019

\author{
Víctor Bastante Granell \\ Profesor Ayudante Doctor de Derecho Civil \\ (Acreditado a Prof. Contratado Doctor) \\ vbg415@ual.es \\ Universidad de Almería
}

Lucía Moreno García

Profesora Ayudante Doctora de Derecho Procesal

Img567@ual.es

Universidad de Almería

\section{RESUMEN}

La "Ludoteca Jurídica" es una plataforma digital que nace como apuesta por la innovación docente en Derecho, particularmente por la "gamificación". El presente trabajo pretende exponer los orígenes de tal proyecto educativo, su fundamento, sus objetivos, su contenido - con especial mención a las fichas de juegos educativos - y las distintas formas de colaboración. Estamos ante una plataforma educativa que postula la defensa de la "gamificación" como metodología complementaria, busca la creación de una red nacional de "gamificadores" y pretende fomentar la educación compartida, así como el uso de las nuevas tecnologías en la enseñanza de las disciplinas jurídicas.

\section{PALABRAS CLAVES}

Gamificación, ludificación, Derecho, educación superior, innovación docente.

\section{ABSTRACT}

The "Ludoteca Jurídica" is a digital platform that was born as a bet for the teaching innovation in law, particularly "gamification". This paper aims to explain the origins of such an educational project, its foundation, its objectives, its content — with special mention of the educational games - and the different forms of collaboration. We are facing an educational platform that postulates the defense of "gamification" as a complementary methodology, seeks the creation of a national network of "gamifiers" and aims to promote shared education, as well as the use of new technologies in the teaching of legal disciplines.

\section{KEYWORDS}

Gamification, law, higher education, teaching innovation 
Sumario: 1. Ludoteca jurídica: ¿Qué es y cómo surgió?. 2. La "gamificación" en Derecho. 2.1 Concepto de "gamificación. 2.2. Elementos de los juegos. 2.3. De la "crítica" a la defensa de sus ventajas. 3. Juegos educativos de la Ludoteca jurídica. 4. Formas de colaboración: Hacia una red nacional sobre "gamificación" en Derecho. 5. Fomento de la educación 3.0 en Derecho. 6. Presente y futuro de la Ludoteca jurídica. Bibliografía.

\section{Ludoteca jurídica: ¿Qué es y cómo surgió?}

La "Ludoteca jurídica" es una plataforma digital educativa que tiene como objetivo principal fomentar la "gamificación" o "ludificación" en Derecho". Ello significa que estamos ante una página web que busca potenciar el aprendizaje del Derecho a través de la aplicación de juegos educativos en las aulas universitarias. En concreto, la plataforma digital pone a disposición del alumnado y profesorado un espacio web que recoge distintas fichas de juegos para que puedan ser utilizadas en las aulas de Derecho, promoviendo la "gamificación" como metodología de aprendizaje complementaria dentro de la enseñanza de disciplinas jurídicas. No obstante, su contenido también está formado - y estará formado- por cuestionarios tipo test online de Derecho, casos prácticos, información de herramientas digitales docentes (Kahoot, Socrative, etc.), etc. Se trata de una plataforma web que busca facilitar, mejorar y desarrollar la enseñanza del Derecho, así como la innovación docente.

Dicha plataforma digital, por el momento, presenta las siguientes características: 1) Constituye una plataforma educativa, que contribuye a la evolución de los procesos de aprendizaje y enseñanza en Derecho a través de la "gamificación" y otros materiales y herramientas docentes; 2) Se trata de una plataforma de carácter abierto y gratuita para el alumnado y profesorado; 3) nos encontramos, en cierto modo, ante una plataforma de educación P2P (peer to peer), puesto que los profesores universitarios, que lo deseen, pueden colaborar con la creación y desarrollo de juegos educativos, así como de otros materiales (exámenes tipo test online, casos prácticos, etc.) —aunque sean objeto de revisión-, compartiendo con otros profesores y alumnos sus juegos, trabajos y conocimientos; y, por último, 4) pretende ser una plataforma de carácter interdisciplinar.

\footnotetext{
${ }^{1}$ Puede acceder a la plataforma digital a través del siguiente enlace web: https://ludotecajuridica.es/ [Fecha de consulta: 22/11/2019]. Hay que destacar, cómo algunas Universidades, como la Facultad de Derecho de Girona, crearon una ludoteca para fomentar, entre otros aspectos, la gamificación en las disciplinas jurídicas. Vid. RUDA GONZÁLEZ, A. y YOLDI ALTAMIRANO, C. (2014). "Aprender jugando. Experiencias de aprendizaje mediante juegos en la Facultad de Derecho de la UdG", Revista CIDUI, № 2, pág. 4 y ss.
} 


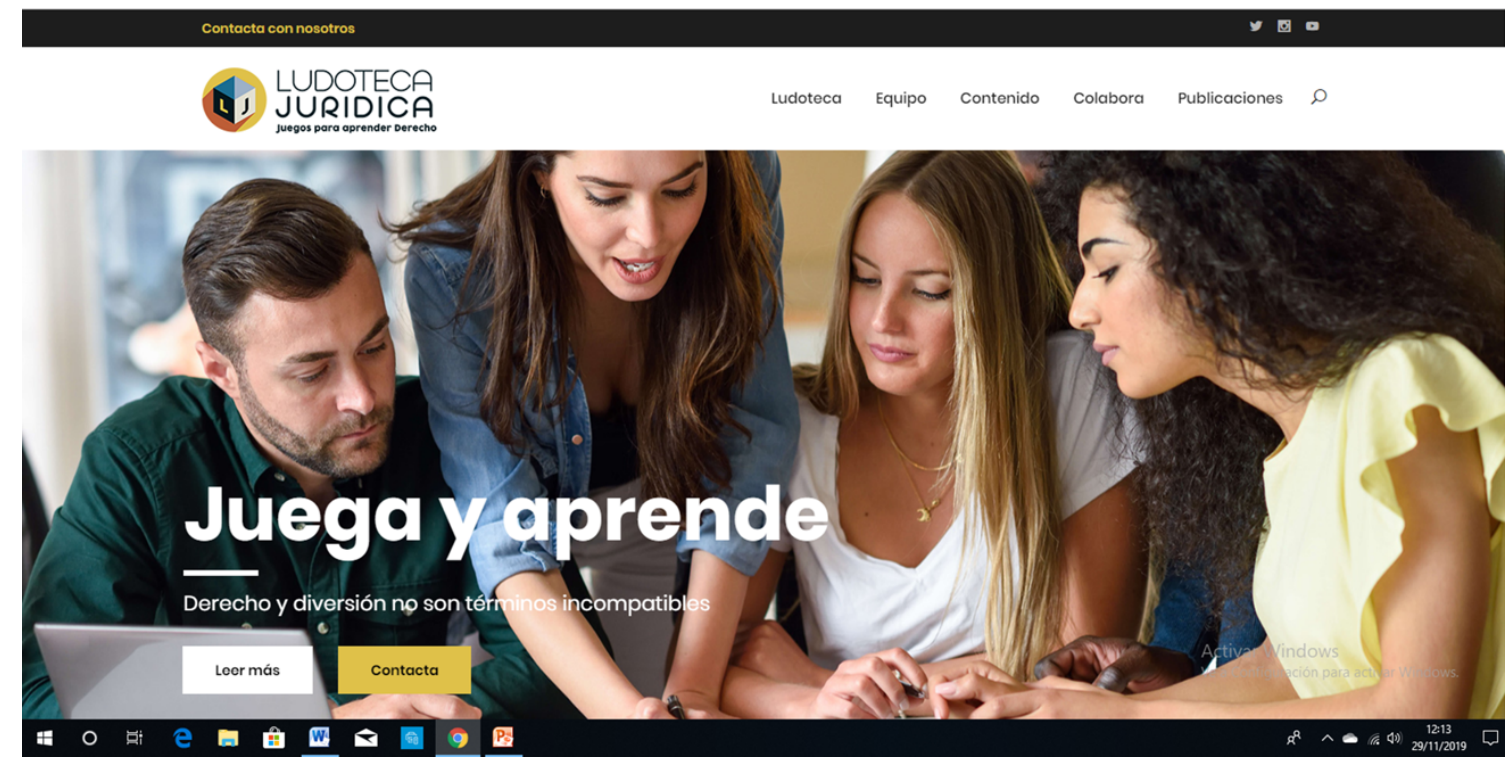

Ilustración $n^{\circ}$ 1: Portada plataforma digital "Ludoteca jurídica".

En cuanto a su origen, debe mencionarse que la "Ludoteca jurídica" es fruto de un proyecto de innovación docente titulado "Juegos educativos para aprender Derecho", concedido en la Convocatoria para la Creación de Grupos de Innovación y Buenas Prácticas Docentes en la Universidad de Almería (Bienio 2018 y 2019), de la Universidad de Almería; y coordinado por el Prof. Víctor Bastante Granell. Dicho proyecto, unido a la voluntad e ilusión de docentes de diferentes disciplinas jurídicas - de los cuales, algunos conforman actualmente el equipo de la "Ludoteca jurídica"2_ constituyó el punto de arranque de tal plataforma digital, que pretende evolucionar y mejorar con el paso de los años.

\section{La "gamificación" en Derecho.}

\subsection{Concepto de "gamificación".}

El vocablo "gamificación" procede del término inglés gamification. Este anglicismo se define por la aplicación de elementos y técnicas propias de los juegos en entornos o ambientes no lúdicos - como puede ser el educativo o el ámbito corporativo de una empresa- ${ }^{3}$.

\footnotetext{
${ }^{2}$ Víctor Bastante Granell (Prof. Ayudante Doctor de Derecho Civil. Acreditado a Contratado Doctor); María Angustias Martos Calabrús (Prof. ${ }^{a}$ Titular de Derecho Civil); María del Mar Gómez Lozano (Prof. ${ }^{a}$ Titular de Derecho Mercantil); Cristina Cano Ortega (Prof. ${ }^{a}$ Ayudante Doctor de Derecho Mercantil. Acreditada a Contratado Doctor); María Luisa Roca Fernández-Castanys (Prof. ${ }^{a}$ Titular de Derecho Administrativo); Alejandro David López Leiva (Prof. Ayudante Doctor de Derecho Administrativo. Acreditado a Contratado Doctor); Marina Aguilar Rubio (Prof. ${ }^{a}$ Titular de Derecho Financiero y Tributario); Raquel Bonachera Villegas (Prof. ${ }^{a}$ Titular de Derecho Procesal); Lucía Moreno García (Prof. ${ }^{a}$ Ayudante Doctora de Derecho Procesal).

${ }^{3}$ Sobre el concepto de "gamificación" pueden consultarse, entre otros autores, HUNTER, D. y WERBACH, K. (2014), Gamificación. Revoluciona tu negocio con las técnicas de los juegos. Madrid: Perarson, pág. 28; BORRÁS GENÉ, O. (2015), Fundamentos de la gamificación. Madrid: Gabinete de Tele-Educación de la Universidad Politécnica de Madrid, pág. 4; y RODRÍGUEZ, F. y SANTIAGO, R. (2015), Gamificación: cómo motivar a tu alumnado y mejorar el clima en el aula. Madrid: Digital-Text. Grupo Océano, págs. 8 y ss. Asimismo, puede verse la definición de gamification facilitada por Fundéu BBVA en
} 
Coloquialmente se utiliza, además de la voz "gamificación", el término "ludificación" como equivalente al español del anglicismo gamification. Hemos de señalar que, a la fecha de elaboración de este trabajo, el diccionario de la lengua española todavía no contempla ninguno de esos dos términos. Ello ha llevado a los autores a plantearse qué vocablo utilizar —si "gamificación", "ludificación" o incluso la palabra inglesa gamification - En este contexto, SÁNCHEZ APARICIO señala que se trata de términos diferentes, pues mientras que "gamificación" se refiere a una metodología — consistente en la aplicación de técnicas y mecánicas de los juegos en contextos no lúdicos-, "ludificación" sería un término más genérico, referido a "hacer que una actividad sea

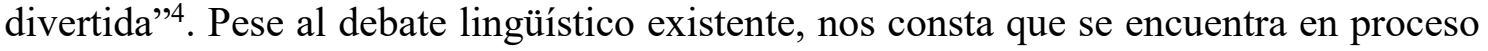
de estudio la incorporación al diccionario de la alternativa en español de gamification. Teniendo en cuenta que, a día de hoy, se está imponiendo el vocablo "gamificación", auguramos que finalmente será este el término que se incorpore ${ }^{5}$.

Con independencia del término que se emplee, hemos de señalar que, en el ámbito educativo, la finalidad principal de esta metodología es activar la motivación del alumnado por el aprendizaje, al tiempo que se aumenta su compromiso, concentración y esfuerzo $^{6}$. No debemos olvidar que, aunque en estos entornos se utilicen mecánicas propias de los juegos, el propósito perseguido sigue siendo formativo. Lo que se pretende con el uso de estas técnicas es acercar al alumno al proceso de aprendizaje y motivarlo a seguir la asignatura.

Además de lo anterior, como indica algún especialista en la materia, la aplicación de la gamificación en las aulas contribuye a que el aprendizaje sea más significativo, puesto que permite "mayor retención en la memoria" del alumno al presentarse la actividad de forma más atractiva ${ }^{7}$. Como señalamos posteriormente, son tantas las ventajas y beneficios de la gamificación que cada vez se está utilizando más como técnica de aprendizaje en la Enseñanza Superior. En lo que respecta a los Estudios de Derecho, el

\footnotetext{
https://www.fundeu.es/recomendacion/ludificacion-mejor-que-gamificacion-como-traduccion-degamification-1390/ [fecha de consulta: 28/11/2019].

${ }^{4}$ SÁNCHEZ APARICIO, J. C. (2016), "Gamificación, gamification, ludificación... ¿cómo me llamo?", entrada publicada en el blog 'El diario de Snackson'; disponible en www.snackson.com [fecha de consulta: 27/11/2019]. En sentido similar, GÓMEZ GARCÍA considera que el término ludificación "se queda en la superficie", pues para este autor este vocablo se refiere a los aspectos lúdicos o divertidos, pero no tiene en cuenta la "reglamentación característica de los juegos organizados". V. GÓMEZ GARCÍA, I. (2015), "Gamificación como recurso de la ingeniería en comunicación social", Revista 'Razón y Palabra', No 90, pág. 6; disponible en www.razonypalabra.org.mx.

${ }^{5}$ En 2018, la RAE anunció que estaban estudiando la incorporación al diccionario académico de la voz "ludificación" como el equivalente español del anglicismo gamification. Incluso aconsejaban la utilización de este término en lugar de "gamificación". Según indicaron en ese momento, sería más apropiado el término "ludificación" al formarse con la raíz latina "ludus" (juego). Sin embargo, hemos de señalar que ante las consultas de los usuarios, la RAE manifestó que para los neologismos esperan "a poder comprobar cuál se asienta en el uso y es preferido por los especialistas". Es por ello que aún no se ha incorporado ninguno de ellos. Teniendo en cuenta esa afirmación, auguramos que se terminará incorporando al diccionario el término "gamificación" como equivalente español del anglicismo gamification, pues a día de hoy es el más extendido entre los especialistas. Lo manifestado por la RAE ha sido extraído de su cuenta oficial de twitter (usuario: @RAEinforma), entradas de 24 de septiembre y 3 de octubre, ambas de 2018.

${ }^{6}$ En este sentido, vid. LÓPEZ LAGO, N. (2016), "Cómo aplicar la gamificación o ludificación educativa en el aula", en el Blog CEAC del Grupo Planeta Formación y Universidades; disponible en https://www.ceac.es/blog/como-aplicar-la-gamificacion-o-ludificacion-educativa-en-el-aula [fecha de consulta: 28/11/2019]; CONTRERAS ESPINOSA, R. S. y EGUIA, J. L. (2016), "Gamificación en aulas universitarias", en CONTRERAS, R. S. y EGUIA, J. L.: Gamificación en aulas universitarias. Bellaterra: Institut de la Comuninicació, Universitat Autònoma de Barcelona, pág. 7.

${ }^{7}$ Cfr. BORRÁS GENÉ, O. (2015), cit., pág. 5.
} 
empleo de esta metodología es mínimo. Sin embargo, desde la Ludoteca Jurídica animamos a todos los docentes a incorporar técnicas de gamificación en algunas de sus actividades, puesto que la gamificación puede ser una buena estrategia de aprendizaje y motivación del alumnado.

Junto con la "gamificación" suele hablarse de los serious games o "juegos serios". Según señalan los autores, aunque ambos conceptos se asocian con el juego, realmente tienen significados diferentes. Como hemos indicado anteriormente, la "gamificación" supone aplicar técnicas y elementos de los juegos en ambientes no lúdicos, como es la educación. De esta definición se infiere que la "gamificación" no es un juego en sí mismo, sino el uso de elementos de estos con la finalidad de motivar a los participantes a realizar una actividad o llevar a cabo una determinada conducta. Sin embargo, como establecen RODRÍGUEZ y SANTIAGO, un serius game sí es un juego, pero la finalidad de este no es tanto hacer más atractiva o motivadora una tarea o actividad cotidiana, como alcanzar "un propósito de aprendizaje concreto" 8 . Con ambas técnicas didácticas se puede enseñar Derecho, la diferencia estriba en que cuando "gamificamos" aplicamos algunos elementos del juego para hacer más atractivas las actividades o tareas que han de desarrollarse durante el curso; con un serious games, realizamos un juego con la finalidad de mejorar el aprendizaje sobre aspectos concretos ${ }^{9}$.

Si bien se mira, ambos conceptos están interrelacionados, tanto es así que para HUNTER y WERBACH los serious games son supuestos especiales de gamificación. Como señalan estos autores, un serious game es un claro ejemplo de uso de las técnicas de los juegos en ambientes que no son de juego, lo único que aquí se llegan a "crear juegos completamente funcionales" 10 . En este entendimiento, puede considerarse que, en ambos casos, estamos "gamificando".

Como se observará más adelante, la "Ludoteca jurídica" facilita fichas educativas que constituyen verdaderos serious games, pero también ofrecemos otras que utilizan meras técnicas de gamificación para motivar al alumnado a realizar ciertas actividades o tareas. Posteriormente, exponemos las distintas fichas y herramientas disponibles en la plataforma digital "Ludoteca jurídica".

\subsection{Elementos de los juegos.}

Como hemos indicado supra, la gamificación es el uso de los elementos y técnicas propias de los juegos en contextos no lúdicos. Ello nos lleva a determinar los elementos que pueden ser utilizados en los procesos de "gamificación".

En este contexto, los autores suelen categorizar los elementos de los juegos en dinámicas, mecánicas y componentes ${ }^{11}$. Por mecánicas se suele entender "los procesos

\footnotetext{
${ }^{8}$ Cfr. RODRÍGUEZ, F. y SANTIAGO, R. (2015), cit., pág. 12. Asimismo, resulta ilustrativo lo manifestado por GRAU, J. (2016), "La diferencia entre gamificación y serious game", en www.beprimsa.com [fecha de consulta: 28/11/2019]. Según este autor, la principal diferencia entre "gamificación" y "serious game" es que mientras la gamificación "es un juego parcial", un serious games es un "juego completo". Para este autor, la gamificación utiliza los elementos propios de los juegos en ambientes no lúdicos para hacer más atractivas tareas o actividades diarias que realizamos en esos contextos o entornos. En cambio, un serious games es un juego en sí mismo, aunque como señala el autor, lo aprendido en estos juegos puede ser útil para nuestras actividades o tareas diarias.

${ }^{9}$ En este sentido, GARCÍA JIMÉNEZ destaca que la finalidad principal de un serious games es "mejorar el aprendizaje en algún aspecto concreto"; GARCÍA JIMÉNEZ, A. (2017), cit.

${ }^{10}$ Cfr. HUNTER, D. y WERBACH, K. (2014), cit., pág. 36.

${ }^{11}$ Así, entre otros, HUNTER, D. y WERBACH, K. (2014), cit., págs. 82 y ss.; GÓMEZ GARCÍA, I. (2015), cit., págs. 7-8; BORRÁS GENÉ, O. (2015), cit., págs. 13 y ss.; CONTRERAS ESPINOSA, R. S.
} 
básicos que hacen progresar la acción y que llevan a que el jugador se involucre"12. Las dinámicas representan algo más abstracto: "los efectos, motivaciones y deseos que se pretenden generar en el participante" 13 . Y los componentes son los elementos concretos que se asocian a los dos elementos anteriores, como serían los avatares, las tablas de clasificación, las insignias o los puntos ${ }^{14}$. Algunos autores examinan las mecánicas junto con los componentes del juego, pues estos son la forma de representar y hacer visible el avance del participante en el mismo ${ }^{15}$.

En la educación, los elementos que suelen utilizarse en los sistemas de gamificación son los siguientes:

- Puntos: son las representaciones numéricas de lo que se consigue al realizar una acción de forma correcta ${ }^{16}$. Como señalan los autores, los sistemas de puntos son muy útiles, pues dan información sobre el progreso del participante y sobre si la acción realizada es correcta o incorrecta ${ }^{17}$.

- Niveles: son los "pasos definidos en la progresión de un jugador"18. Al igual que los puntos, muestran los avances conseguidos por el participante ${ }^{19}$. Los niveles suelen asociarse a la superación de determinadas etapas o fases.

- Tablas de clasificación: permite al participante conocer su posición en el sistema gamificado y compararla con el del resto de jugadores. Como señalan los autores, este elemento del juego puede ser muy motivador, pues muchos participantes querrán alcanzar la cima de la clasificación al conocer el puesto que ocupa el resto de jugadores. Sin embargo, como también alertan los especialistas, si la tabla no se emplea bien puede ser un elemento muy desmotivador para aquellos jugadores que ocupen las posiciones más bajas. En este sentido, HUNTER y WERBACH indican que existen diferentes formas de hacer que las tablas de clasificación funcionen correctamente - pueden hacerse tablas más dinámicas, o incluso presentar varias en las que se valoren distintas características o cualidades de los participantes $-{ }^{20}$.

(2016), "Elementos de juego y motivación: reflexiones entorno a una experiencia que utiliza gamificación en una asignatura de grado para game designers", en CONTRERAS, R. S. y EGUIA, J. L.: Gamificación en aulas universitarias, cit., págs. 57-58; TEIXES, F. (2014), Gamificación: Fundamentos y aplicaciones. Barcelona: UOC Business School, págs. 61 y ss.; y ALEJALDRE DIEL, L. y GARCÍA JIMÉNEZ, A. M. ${ }^{a}$. (2015), "Gamificar: el uso de los elementos del juego en la enseñanza del español”, en Congreso La cultura hispánica: de sus orígenes al siglo XXI. Burgos: Publicaciones de la Asociación Europea de Profesores de Español, págs. 75 y ss.

${ }^{12}$ HUNTER, D. y WERBACH, K. (2014), cit., pág. 83.

${ }^{13}$ BORRÁS GENÉ, O. (2015), cit., pág. 13, con cita a HERRANZ (2013).

${ }^{14}$ Cfr. BORRÁS GENÉ, O. (2015), cit., págs. 14-15.

${ }^{15}$ Así, TEIXES, F. (2014), cit., pág. 61.

${ }^{16}$ Como indican HUNTER y WERBACH, los puntos son las "representaciones numéricas de la progresión dentro del juego"; HUNTER, D. y WERBACH, K. (2014), cit., pág. 84.

${ }^{17}$ Cfr. BORRẢS GENÉ, O. (2015), cit., pág. 17, y TEIXES, F. (2014), cit., pág. 61.

${ }^{18}$ HUNTER, D. y WERBACH, K. (2014), cit., pág. 84.

${ }^{19}$ Como señala BORRÁS GENÉ, los niveles pueden indicar el "estado de un usuario y el dominio sobre un sistema" -lo que le permite compararse con otros participantes-, o "el progreso" del mismo dentro del sistema. En este caso, el participante puede valorar su progreso y lo que le queda para finalizar. Cfr. BORRÁS GENÉ, O. (2015), cit., pág. 18.

${ }^{20}$ Cfr. HUNTER, D. y WERBACH, K. (2014), cit., págs. 80-81. 
- Medallas o insignias: son definidas como la "representación visual de un logro específico dentro del sistema gamificado" 21 . Un ejemplo claro de "medalla" o "insignia" lo encontramos en el juego "Duolingo", en el que se premia el esfuerzo $\mathrm{y}$ constancia del jugador mediante el otorgamiento de "coronas" y reconocimientos por los "logros" alcanzados.

- Retos o desafios: son pruebas de mayor dificultad a las que se somete a los participantes del sistema gamificado o de un serious games. Las mismas exigen un mayor esfuerzo por parte del participante ${ }^{22}$.

- Avatares: son las "representaciones visuales del personaje de un jugador"23. Mediante el uso de avatares el participante puede identificarse dentro del sistema gamificado o de un serious game. Los avatares provocan una mayor implicación del participante en el sistema, pues como indica TEIXES, los jugadores suelen mostrar un "mayor apego emocional" por el mismo ${ }^{24}$.

- Premios o recompensas: son los beneficios que puede conllevar la realización de una determinada actividad o la superación de un logro específico ${ }^{25}$.

- Entre otros muchos, como los combates, los logros, las misiones, el uso de turnos, la formación de equipos, etc.

Los elementos del juego descritos pueden utilizarse para "gamificar" alguna de nuestras actividades o tareas de clase. Asimismo, podemos emplearlos para crear serious games sobre materias concretas. En apartados posteriores, mostramos algunos ejemplos de cómo podemos utilizar las herramientas de los juegos en las aulas de Derecho.

\subsection{De la "crítica" a la defensa de sus ventajas.}

La enseñanza de disciplinas jurídicas se ha caracterizado por el uso de metodologías docentes de carácter tradicional. Aunque ciertamente se ha producido una renovación de las mismas - mediante el uso de las TIC's - se ha obviado la posibilidad de que el Derecho, cómo rama del conocimiento, se puede aprender "jugando". La "gamificación" del aprendizaje jurídico y su aplicación puede —y debe- convertirse en una metodología docente complementaria en la enseñanza de disciplinas jurídicas. Se manifiesta, en este sentido, que "el juego es un activador en la atención y surge como alternativa para complementar los esquemas de enseñanza tradicional" 26 . Ante ello, y como bien señala Tom Peters, "toca ponerse la camiseta de gamificador" ${ }^{27}$, pero, esta vez, en el ámbito de la enseñanza del Derecho, no en el ámbito empresarial, en interés de la educación superior.

No obstante lo anterior, somos conscientes de que la aplicación de la gamificación en las disciplinas jurídicas está siendo objeto de diversas críticas. Tales críticas, muy respetables, conciben el juego como un mecanismo de ocio y entretenimiento, no apto para la formación jurídica. Si bien, no puede concebirse la "gamificación" como una forma de banalizar el Derecho o, en su caso, como una metodología que únicamente

\footnotetext{
${ }^{21}$ BORRÁS GENÉ, O. (2015), cit., pág. 17.

${ }^{22}$ Cfr. HUNTER, D. y WERBACH, K. (2014), cit., pág. 83; y ALEJALDRE DIEL, L. y GARCÍA JIMÉNEZ, A. M. ${ }^{\text {. }}$ (2015), cit., pág. 77.

${ }^{23}$ HUNTER, D. y WERBACH, K. (2014), cit., pág. 84.

24 TEIXES, F. (2014), cit., pág. 67.

${ }^{25}$ Al respecto, v. HUNTER, D. y WERBACH, K. (2014), cit., pág. 83.

${ }^{26}$ LOZADA ÁVILA, C. y BETANCUR GÓMEZ, S. (2017). "La gamificación en la educación superior: una revisión sistemática”, Revista Ingenierías Universidad de Medellín, vol. 16, No. 31 pág. 99.

${ }^{27}$ Frase citada en RODRÍGUEZ, F. y SANTIAGO, R. (2015), cit., pág. 5.
} 
permita desarrollar un razonamiento jurídico superficial. No hemos de olvidar que no se trata de "jugar" sin más, como mera actividad de entretenimiento, sino de usar las técnicas de los juegos como metodología docente complementaria. Dicho con otras palabras, se trata de usar tales técnicas en la enseñanza de las disciplinas jurídicas, siempre -y claro está- que permita al alumnado la adquisición de competencias y el desarrollo de capacidades. De no ser así, no podríamos hablar de "gamificación" o "serious game", sino de mera diversión, recreo o pasatiempo. Como señalan ciertos autores, "existen muchos/as docentes escépticos/as, ya sea por desconocimiento, miedo al cambio, las dificultades del mismo o falsas creencias sobre incompatibilidades con el sistema" ${ }^{28}$. Aun así, diversos profesores de Derecho defienden su uso en las aulas universitarias ${ }^{29}$. La "Ludoteca jurídica" constituye una apuesta por un cambio de percepción.

La RAE, al definir la palabra "jugar", alude a la posibilidad de adquirir competencias: "Hacer algo con alegría con el fin de entretenerse, divertirse o desarrollar determinadas capacidades". La "gamificación" supone usar elementos de diseño propios de los juegos en contextos no lúdicos (ámbito empresarial, laboral, etc.) con la finalidad de obtener diferentes resultados que, en el plano educativo, serían los siguientes: a) potenciar la motivación $^{30}$, compromiso (engagement) y atención del alumno (cuanta mayor sea la implicación mayor será el aprendizaje); b) reforzar su conducta y ánimo de superación para obtener objetivos; c) activar su aprendizaje y participación ${ }^{31}$; d) facilitar y reforzar la interiorización de conocimientos de una forma entretenida; e) mejorar habilidades y

\footnotetext{
${ }^{28}$ BARBOSA GONZÁLEZ, A., RAPOSO RIVAS, M. y MARTÍNEZ FIGUEIRA, E. (2018). "Recursos para analizar el diseño y puesta en práctica de la gamificación en el aula”, en LÓPEZ-MENESES, E., COBOS-SANCHIZ, D., MARTÍN-PADILLA, A., MOLINA-GARCÍA, L. y JAÉN-MARTÍNEZ, A.: Experiencias pedagógicas e innovación educativa: Aportaciones desde la praxis docente e investigadora. Barcelona: Octaedro, pág. 850.

${ }^{29}$ Vid. RUDA GONZÁLEZ, A. y YOLDI ALTAMIRANO, C. (2014), cit.

30 "La motivación de los estudiantes es un factor determinante en el proceso de aprendizaje, que permite a los profesores conectar a los estudiantes con la clase, el profesor debe progresar en la búsqueda de elementos que se conviertan en motivadores, con el fin de lograr atención en sus clases, involucrando a sus estudiantes y creando interacciones efectivas dentro del aula, para desarrollar conocimiento y no sólo dar información que luego será olvidada el siguiente día o la siguiente semana”. VÉLEZ OSORIO, I. M. (2016), "La gamificación en el aprendizaje de los estudiantes universitarios", Rastros Rostros, Vol. 18, № 33, pág. 35. Es importante hallar la forma correcta de fomentar la motivación: "A nivel individual, para gamificar una actividad es necesario encontrar la forma correcta de motivar a la persona adecuada en el momento adecuado. Por ello, es importante conocer las diferentes motivaciones, que pueden ser de dos tipos: a) intrínsecas: inherente a la persona, lo realiza por su propio bien o interés (por ejemplo: estatus, poder, acceso a ciertas aptitudes) o para contribuir a un bien común y b) extrínsecas: exterior a la persona, lo realiza por la recompensa o feedback. También es importante el componente social, o lo que es lo mismo, el contar con otras personas con las que competir, colaborar y comparar logros. En el juego social, los objetivos pueden ser competitivos o colaborativos. Por ello, en juegos de equipo deben ser consideradas por separado las mecánicas que influyen en el equipo (proyectos, puntuaciones de grupo, etc.), de las mecánicas que solo se aplican al individuo (motivación, el refuerzo positivo, etc.). GONZÁLEZ GONZÁLEZ, C. S. y MORA CARREÑO, A. (2014). "Propuesta metodológica de gamificación en la enseñanza técnica superior”, en Actas del XVI Simposio Internacional de Informática Educativa (SIIE' 14): Acceso masivo y universal para un aprendizaje a lo largo de la vida. Logroño: UNIR-Universidad Internacional de La Rioja, pág. 52.

${ }^{31}$ Tras una experiencia docente, se llegó a la siguiente conclusión: "Se evidencia entonces que el sistema de gamificación permite materializar contenidos teóricos hacia aplicaciones en el campo real, en ejercicios de clase para que el estudiante comprenda ampliamente la razón de ser de los contenidos de las asignaturas, y no solamente perciba el curso como necesario sino enriquecedor. Además, trasforma la relación entre profesor y estudiante, basado en unas metodologías para el aprendizaje complementarias a la gamificación y la intervención del profesor para que todo el proceso sea un engranaje de transformación educativa". VÉLEZ OSORIO, I. M. (2016), cit., pág. 29.
} 
competencias (transformar conocimientos en competencias); f) estimular la "competencia sana" y la conexión social; g) obtener la fidelización del alumno con el contenido que trabaja; h) optimizar y recompensar al alumno; i) enseñar a trabajar en equipo, resolver problemas o respetar las opiniones ajenas (según el juego aplicado). En resumen, como indican RODRÍGUEZ y SANTIAGO:

"Su objetivo en el terreno de la educación no es otro que llevar la motivación al proceso de enseñanza y aprendizaje, mediante la incorporación de elementos y técnicas del juego. Un proceso que, bien utilizado, incorpora unas extraordinarias ventajas a la hora de enriquecer la relación entre docentes y alumnos mejorando así el clima en el aula. No olvidemos que los alumnos aprenden solo de aquellos educadores que son capaces de motivarles, de inspirarles, de sacar lo mejor que tienen dentro" 32 .

Aunque la "gamificación" sigue siendo objeto de estudio en el ámbito educativo sobre todo, en la educación superior-, puede comprobarse que aporta numerosos beneficios a los estudiantes. Ciertamente, el equilibrio entre lo lúdico y lo formativo es muy difícil de obtener. Por tal razón, si la actividad pierde su carácter formativo, la "gamificación" sería improductiva en la enseñanza del Derecho. El docente, al crear u aplicar un juego en Derecho no puede olvidar que tal actividad debe desarrollar competencias y habilidades.

No debemos olvidar que "la gamificación es el instrumento, no el fin"33. Lo principal es que el uso de tal metodología se centre en la consecución de un objetivo, que en la rama del Derecho sería la adquisición de competencias en el ámbito jurídico. Por tal razón, lo primero es plantear la acción formativa que se desea, es decir, las competencias y contenidos que el docente pretende que los estudiantes adquieran y aprendan. Luego, será necesario dilucidar el escenario, contexto o tipo de juego adecuado para desarrollar tal acción educativa. Posteriormente se definen las reglas y la mecánica del juego — con base a los elementos y principios de la "gamificación"-, concluyendo con el esbozo de la forma de evaluación de la labor realizada por los estudiantes o, en su caso, grupos. De esta forma, al elaborar un juego el docente debe identificar qué tipo de logro y competencia/s tiene como objetivo alcanzar dentro de la enseñanza de una disciplina jurídica concreta. El resultado, como indica cierta doctrina, es un fomento de la motivación y el aprendizaje implícito:

"La aproximación desde la gamificación puede ejercer una gran influencia en el desarrollo de las competencias requeridas en las titulaciones universitarias, ya que incrementa la participación y la motivación de los sujetos a través de un contexto de juego que facilita el aprendizaje implícito. El estudio gamificado presenta unos objetivos secuenciados y claros destinados a proponer retos alcanzables a corto plazo que dan continuidad al sentido de progresión de los jugadores, proporcionando recompensas que actúan como motivadores externos" ${ }^{\prime 34}$.

Al desarrollar un juego educativo, el docente en Derecho debe guiar su creación atendiendo a las competencias propias del título de Grado de Derecho, aunque también puede inspirarse en el Libro Blanco de la Agencia Nacional de Evaluación de la Calidad y Acreditación ${ }^{35}$. Según dicho documento, debemos centrarnos en el desarrollo de 1) competencias instrumentales (capacidad de análisis y síntesis, capacidad de organización y planificación, comunicación oral y escrita en lengua nativa, conocimientos de

\footnotetext{
${ }^{32}$ RODRÍGUEZ, S. y SANTIAGO, R. (2015), cit., pág. 5.

${ }^{33}$ GUTIÉRREZ-ARTACHO, J. y OLVERA LOBO, M. D. (2017). "Gamificación para la adquisición de competencias en la educación superior: el caso de la traducción e interpretación”, en PADILLA CASTILLO, G.: Aulas virtuales, fórmulas y prácticas. Madrid: McGraw Hill, pág. 203.

${ }^{34}$ GUTIÉRREZ-ARTACHO, J. y OLVERA LOBO, M. D. (2017), cit., pág. 204.

${ }^{35}$ Disponible en: http://www.aneca.es/var/media/150240/libroblanco_derecho_def.pdf [Fecha de consulta: 22/11/2019].
} 
informática relativos al ámbito de estudio, capacidad de gestión de la información, resolución de problemas, capacidad de decisión, etc.), 2) competencias interpersonales (trabajo en equipo, trabajo en un equipo de carácter interdisciplinar, habilidades en las relaciones interpersonales, reconocimiento a la diversidad y la multiculturalidad, razonamiento crítico, compromiso ético, etc.), 3) competencias sistémicas (aprendizaje autónomo, adaptación a nuevas situaciones, creatividad, liderazgo, iniciativa y espíritu emprendedor, etc.), 4) competencias académicas, 5) competencias disciplinares y 6) competencias profesionales ${ }^{36}$. Un único juego educativo se puede convertir en una herramienta educativa eficaz, capaz de aunar múltiples capacidades en materia de Derecho. La "Ludoteca jurídica" es una plataforma digital que pretende mostrar tal realidad, siendo posible actualmente acceder a múltiples fichas de juegos educativos.

\section{Juegos educativos de la Ludoteca jurídica.}

Aunque el contenido de materiales educativos disponibles en la plataforma digital irá aumentando de forma paulatina, actualmente hay disponibles diversos juegos (en la pestaña de "contenido" de la "Ludoteca jurídica" ${ }^{37}$ ) —algunos destinados a una rama del Derecho y otros de carácter interdisciplinar-, diseñado por distintos docentes universitarios, que, aplicados de forma correcta, pueden permitir la adquisición de diferentes habilidades y competencias por el alumnado en las aulas universitarias. Entre las fichas educativas de juegos, podemos mencionar las siguientes:

- Sigue la pista: "Su título obedece a que consiste en intentar descifrar un concepto de Derecho Financiero y Tributario siguiendo las pistas que proporciona el profesor/a. En concreto, los/as alumnos/as, a través de una competición por equipos y el uso de un timbre digital (mediante dispositivo móvil), intentarán dar la respuesta correcta utilizando el menor número de pistas posible, resultando ganador del juego aquel equipo que antes consiga adivinar el concepto que se

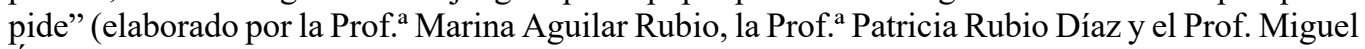
Ángel Luque Mateo).

- Conceptúa: "Busca que los alumnos/as aprendan a formar, construir y sintetizar conceptos jurídicos. A través de una competición por equipos y el uso de un cronómetro, los alumnos/as deben definir conceptos jurídicos (sin mencionar palabras tabúes o prohibidas), mientras que sus compañeros/as de equipo deben averiguar de que palabra se trata en un tiempo determinado. Cuantas más palabras averigüen, más puntos consigue el equipo" (elaborado por el Prof. Víctor Bastante Granell).

- Gametest: "Se configura como forma de repaso de los conceptos básicos de la asignatura, mediante la realización concurrente y competitiva de un test elaborado mediante la utilización de la herramienta digital Kahoot. La innovación frente a los tipos test tradicionales estriba en que los alumnos compiten de forma simultánea mediante el uso de un dispositivo móvil y con un tiempo preestablecido en la respuesta de las preguntas (previamente definido por el profesor). Las preguntas se muestran de forma sucesiva en la pantalla del aula mediante el uso del proyector. Las respuestas correctas son visibles y tras cada contestación en pantalla y en el dispositivo móvil utilizado, lo que permite al alumno/a verificar automáticamente su contestación. La mejor puntuación se establece, no sólo por el acierto de las cuestiones, sino por la mayor rapidez en la contestación. Tras cada pregunta, el sistema ofrece la clasificación automática de los estudiantes mejor situados. Al final del juego se muestra el "Podio" con las tres mejores clasificaciones: oro,

\footnotetext{
36 "Como han señalado múltiples autores, los juegos serios contribuyen a que los estudiantes desarrollen la aptitud relacional, capacidad de atención múltiple, alta motivación al logro, mayor tolerancia a la frustración, capacidad para tomar riesgos, resolver problemas y tomar decisiones, aprendizaje de la reflexión estratégica, creatividad, cooperación, y sentido de la innovación, entre otras ventajas, todo lo cual es crucial en los tiempos actuales". RUDA GONZÁLEZ, A. y YOLDI ALTAMIRANO, C. (2014), cit., pág. 4.

${ }^{37}$ Disponible en: https://ludotecajuridica.es/contenido/ [Fecha de consulta: 22/11/2019].
} 
plata y bronce y la puntuación global obtenida" (elaborado por la Prof. a María Luisa Roca Fernández-Castanys).

- Letra de cambio: "Dos equipos se enfrentan por conseguir la Letra de cambio de mayor importe. Deben responder correctamente hasta un máximo número de 10 preguntas test sobre Títulos Valores para ir sumando dinero a su Letra. Ante la duda, pueden plantarse. Si se equivocan pierden

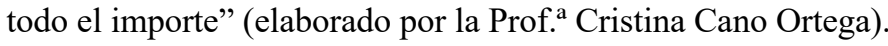

- El adivinador: "Es un juego que consiste en adivinar un concepto jurídico que aparece en la pizarra. Tal concepto deberá ser descubierto por un/a alumno/a (El/la adivinador/a) que se encuentra de espaldas a la pizarra y frente a sus compañeros/as, desconociendo el vocablo escrito. El resto de los alumnos/as, divididos en grupos o de forma individual, (dependiendo del número de alumnado) deberán definir el concepto sin desvelar el nombre del mismo. Puntuará favorablemente el/la alumno/a (o grupo) que adivine el concepto y el que aporte la mejor definición. Cuando el vocablo jurídico sea adivinado, el/la alumno/a dejará su puesto y se incorporará a su grupo (si la clase estuviera dividida por equipos) o, bien, ocupará su sitio de forma individual, asumiendo el rol de adivinador/a el siguiente compañero/a" (elaborado por la Prof. ${ }^{\text {a }}$ Nuria Martínez Sánchez).

- Olimpiada procesal: "Pretende que todos los/as alumnos/as que concursen tengan un conocimiento completo de los distintos procesos a través de los cuales se pueden resolver conflictos. A través de una competición por equipos, con el empleo de un tablero y un dado, los/as alumnos/as han de ir ganado medallas, hasta ganar las olimpiadas del Derecho Procesal. Resultando vencedor el equipo que a la finalización del año académico se mantenga invicto" (elaborado por la Prof. ${ }^{\text {a }}$ Raquel Bonachera Villegas).

- Contratlón: "Dos equipos se enfrentan por ganar una trepidante carrera sobre contratos mercantiles pasando por 3 pruebas distintas. Para la primera tendrán que demostrar sus dotes artísticas dibujando con el objetivo de que sus compañeros adivinen la "parte contractual" de un contrato mercantil. Para la segunda tendrán que realizar un pequeño teatro mudo para que su grupo adivine el nombre del contrato que representan. Y por último, tienen que montar tres puzles contractuales antes que el equipo rival y dentro del plazo de entrega estipulado, el cual habrá aumentado según los aciertos de las dos pruebas anteriores, y adivinando de qué contratos se trata" (elaborado por la Prof. ${ }^{a}$ Cristina Cano Ortega).

- Best Adviser: “A través de tal juego los/as alumnos/as crearán su propia asesoría jurídica. Mediante un juego competitivo, los equipos irán resolviendo distintos problemas jurídicos dentro de un plazo de tiempo estipulado. Los equipos que vayan resolviendo tales problemas podrán robar clientes a las "asesorías" de la competencia. Se anima a los/as alumnos/as a participar en un juego y ver quien se convierte en el mejor asesor (Best advisor) de la clase" (elaborado por el Prof. Víctor Bastante Granell).

- TestLex: "se configura como una forma de iniciar al estudiante a realizar pruebas de conocimiento tipo test mediante la competición con otros equipos de compañeros en clase. Mediante un tiempo máximo de respuesta establecido y saltando al equipo siguiente en caso de error, se va puntuando a cada grupo, ganando aquel que obtenga más puntos. Los test versarán sobre leyes objeto de estudio dentro de la asignatura" (elaborado por el Prof. José Soler Arrebola).

- $\quad$ S.A.BUESOS: "Dos equipos, por turnos, se enfrentan por averiguar el mayor número de palabras posibles relacionadas con el Derecho de sociedades conociendo sólo una pequeña definición y algunas de las letras que componen cada una de ellas en un tiempo limitado. En principio hay un máximo de 10 palabras por equipo, pero pueden aprovechar los rebotes del equipo contrario para acertar más" (elaborado por la Prof. a Cristina Cano Ortega).

- El trovador: "Su denominación obedece a que consiste en un concurso de relatos sobre Historia del Derecho. En concreto, los/as alumnos/as, a través de una competición por equipos y el uso de un timbre digital (mediante dispositivo móvil), se encargan de narrar y responder a preguntas sobre hechos y acontecimientos históricos sobre Derecho, pudiendo usar comodines y preguntas exprés" (elaborado por el Prof. Víctor Bastante Granell).

- Con "C" de concurso: "Es un juego donde dos equipos se enfrentan por acertar las 10 palabras relacionadas con el Derecho concursal que empieza por una determinada letra. Gana el equipo que dentro de su turno acierte más palabras" (elaborado por la Prof. ${ }^{a}$ Cristina Cano Ortega). 
- Find Your Partner: "Encuentra la pareja tiene como objetivo reafirmar los conocimientos adquiridos sobre ciertos términos jurídicos. A través de la competición por equipos los estudiantes deben emparejar los términos jurídicos con su significado, con la institución a la que pertenece o con el artículo donde se regula. Cuantas más parejas se unan, más puntos conseguirá el equipo" (elaborado por la Prof. ${ }^{a}$ María Angustias Martos Calabrús).

- Empresa Loca: "Es un juego de mesa con un tablero compuesto por diferentes casillas por las que el/la alumno/a tiene que avanzar tirando un dado (puede ser mediante dispositivo móvil o uno real), empezando en la primera casilla en la que crea su empresa, y pasando por distintas casillas algunas de las cuales deben responder correctamente a una pregunta para conseguir algún tipo de ventaja o para obtener la menor penalización posible según el caso. Además, los/as alumnos/as cuentan con un dinero inicial para empezar la actividad de la empresa que va a aumentar o disminuir dependiendo del número que saquen en los dados y del dinero que sumen o resten en las casillas especiales. Dentro de cada equipo gana el/la jugador/a que antes llegue a la última casilla y, a su vez, el ganador de todos los equipos será el que habiendo ganado en su equipo haya obtenido el mayor dinero posible" (elaborado por la Prof. ${ }^{a}$ Cristina Cano Ortega).

- Triatlón Fiscal: "Es un juego que, a través de tres pruebas diferentes, pretende que los/as alumnos/as conozcan los conceptos e instituciones básicas del Derecho Financiero y Tributario. Los/as alumnos/as, a través de una competición por equipos y, en dos pruebas del juego, el uso de un timbre digital (mediante dispositivo móvil), intentarán descubrir los conceptos que se ocultan en las diversas pruebas del juego" (elaborado por la Prof. ${ }^{a}$ Marina Aguilar Rubio, la Prof. ${ }^{a}$ Patricia Rubio Díaz y el Prof. Miguel Ângel Luque Mateo).

- Search of Courts: "Búsqueda de Tribunales es un juego de Derecho procesal que consiste en la realización por los alumnos (en equipos) de una especie de gymkhana, en la cual, con la ayuda de diferentes leyes y un mapa, deberán depositar en distintas cajas (que representan los Tribunales), situadas en el campus universitario, una serie de fichas (demandas y recursos) en el menor tiempo posible. De esta lúdica forma, los alumnos aprenderán la importancia de conocer las reglas en materia de competencia dentro de la rama del Derecho Procesal, poniéndose en la piel de un abogado/procurador que debe presentar ciertos escritos en un breve plazo de tiempo" (elaborado por el Prof. Víctor Bastante Granell).

- Proceso express: "Pretende que los/as alumnos/as conozcan de una forma rápida y sencilla el desarrollo de un proceso civil declarativo (ordinario). A través de una competición por equipos, los alumnos/as deben ir superando las distintas fases de un juicio ordinario o de un juicio verbal. Para superar cada fase, deben responder correctamente dos preguntas tipo test sobre la fase en la que se encuentren (dependiendo del tipo de proceso ordinario que se tome como base, juicio ordinario o juicio verbal, el juego tendrá 5 fases — demanda, contestación a la demanda, audiencia previa, juicio y sentencia-, o cuatro fases — demanda, contestación a la demanda, vista y sentencia). Gana el equipo que consiga antes el dictado de la sentencia" (elaborado por la Prof. ${ }^{a}$ Lucía Moreno García).

Dentro de la plataforma digital, accediendo a contenido, concretamente en la sección "Juegos educativos", el docente puede acceder a las fichas de los distintos juegos para visualizarlas en la pantalla o, bien, para descargarla en PDF. Éstas siguen una misma estructura que pretende exponer, de forma clara y sencilla, los diferentes aspectos del juego educativo para que pueda ser interiorizado y aplicado en las aulas de Derecho. En particular, se sigue la siguiente estructura en cuando al contenido: 1) Título del juego; 2) Autor del juego; 3) Resumen; 4) Tipo de juego (individual, por parejas, por grupos, competitivo, colaborativo, dirigido, interior, exterior, etc.); 5) Fases para su desarrollo en clase (elaboración de materiales, fichas, formación de equipos, etc.); 6) Materiales necesarios para su aplicación en clase; 7) Reglas del juego; 8) Ilustración de la "dinámica" del juego; 9) Tiempo de duración; 10) Competencias y habilidades que se trabajan con el juego educativo ${ }^{38}$; 11) Formas de valoración/evaluación de los resultados; 12) y, finalmente, una frase que recoge la experiencia del docente que creó y diseño el juego.

\footnotetext{
${ }^{38}$ Son competencias extraídas de las titulaciones oficiales del Grado de Derecho.
} 
Además, dentro de la plataforma, debajo de la ficha del juego, hay disponible una encuesta que el docente puede remitir a los alumnos para su contestación y, de esta forma, observar el grado de satisfacción con el juego aplicado. Ello, en aras a mejorarlo o efectuar modificaciones que permitan un desarrollo óptimo ${ }^{39}$.

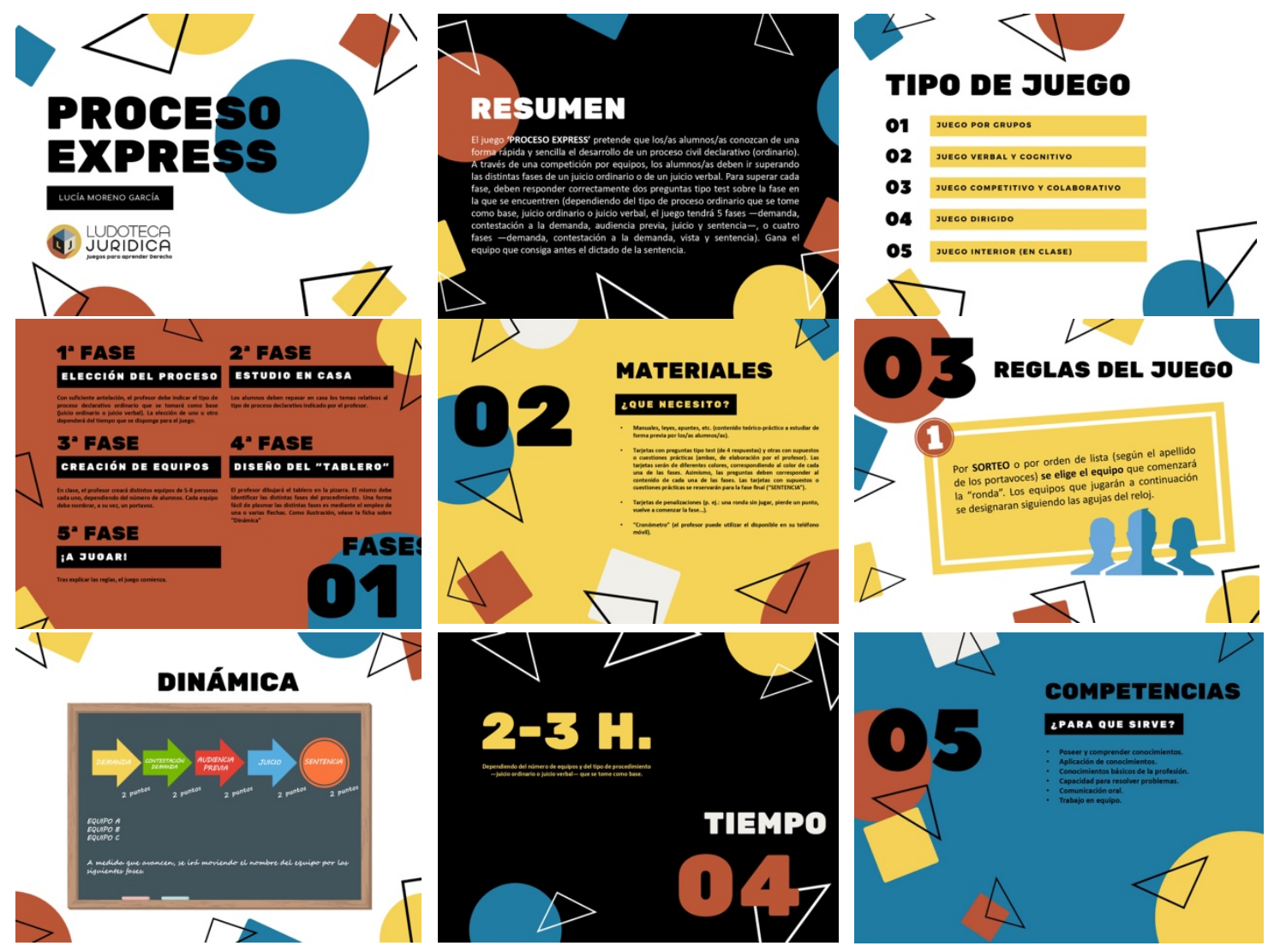

Ilustración no 2: Formato ficha de juego educativo (Juego "Proceso express").

La plataforma digital permite al profesorado realizar una encuesta sobre el grado de satisfacción de los alumnos con el juego educativo que se haya empleado en el aula. Actualmente, observando los resultados de ciertas encuestas, puede observarse que existe un alto grado de satisfacción por los estudiantes. En concreto, el formulario recoge las siguientes preguntas: 1) Indica tu nivel de satisfacción con el juego realizado; 2) ¿Te ha parecido interesante aprender Derecho mediante un juego educativo?; 3 ) ¿Consideras que puede ser útil el uso de juegos para mejorar la motivación de los alumnos?; 4) ¿Te gustaría que se hiciera un mayor uso de juegos educativos en clases de Derecho?; 5) ¿Los profesores suelen utilizar juegos educativos en clase?; 6) ¿Qué hubieras cambiado del juego educativo aplicado en clase?. A modo de ejemplo, respecto al juego "Conceptúa" - creado por el Prof. Víctor Bastante - , tras realizar la encuesta a 103 estudiantes, se han extraído los siguientes porcentajes y conclusiones: 1) El nivel general de satisfacción ha sido de notable y sobresaliente; 2) A más del 70\% del alumnado le ha parecido interesante aprender Derecho a través de un juego educativo; 3) El 80\% de los estudiantes considera

\footnotetext{
${ }^{39}$ En dicha encuesta se preguntan las siguientes cuestiones: Nivel de satisfacción con el juego realizado; si ha resultado interesante aprender Derecho mediante un juego educativo; si, tras la experiencia docente, se considera que puede ser útil el uso de juegos para mejorar la motivación de los/as alumnos/as; si a la persona le gustaría que se hiciera un mayor uso de juegos educativos en clases de Derecho; si los profesores/as suelen utilizar juegos educativos en clase; o, bien, qué hubieran cambiado del juego educativo.
} 
útil aplicar la "gamificación como metodología complementaria; 4) El 98\% de los encuestados demanda un mayor uso de dicha técnica en las aulas; y, por último, 5) los alumnos manifiestan que dicha metodología apenas - por no decir nunca - es utilizada por otros profesores.

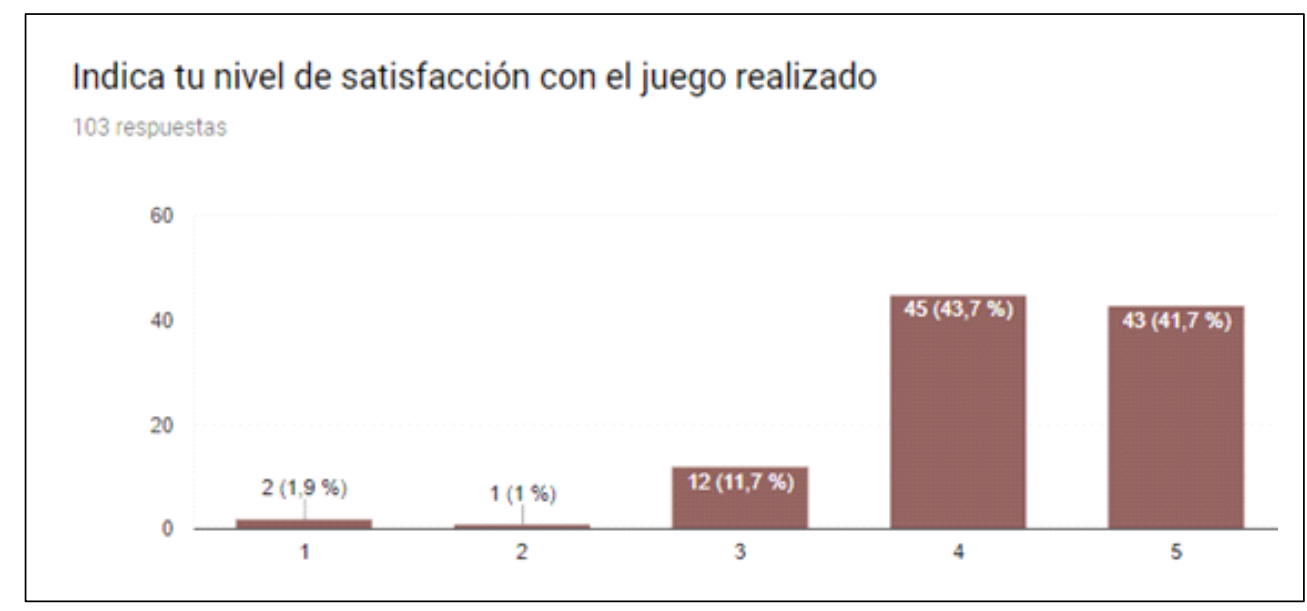

¿Te ha parecido interesante aprender Derecho mediante un juego educativo?

103 respuestas

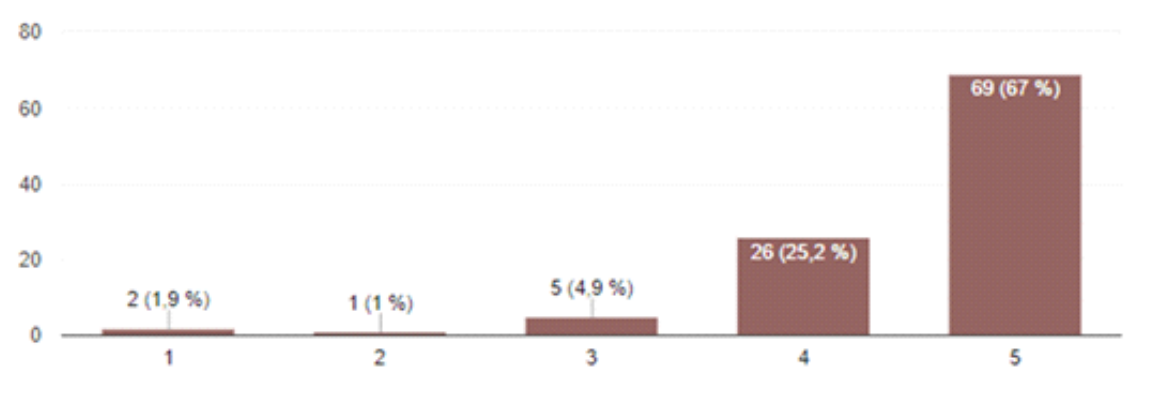

¿Consideras que puede ser útil el uso de juegos para mejorar la motivación de los/as alumnos/as?

103 respuestas

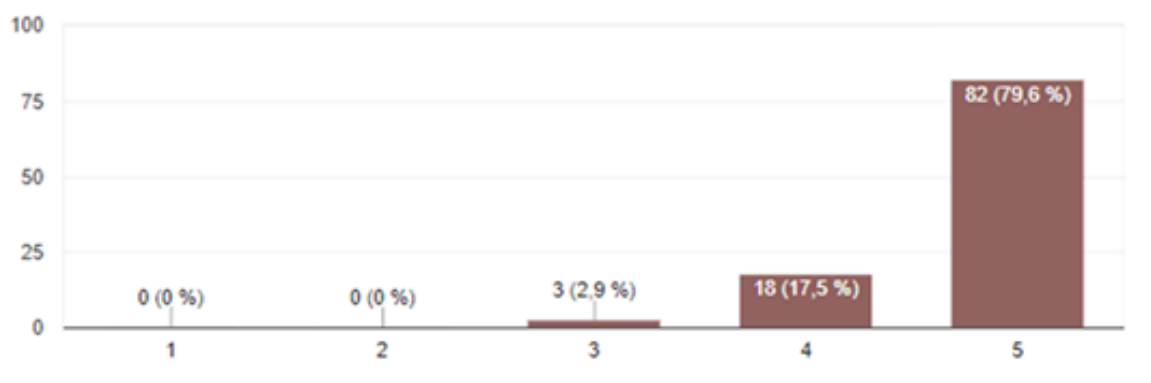


¿Te gustaría que se hiciera un mayor uso de juegos educativos en clases de Derecho?

103 respuestas

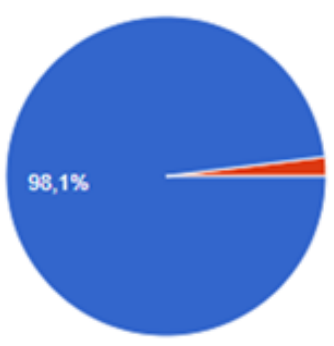

¿Los/as profesores/as suelen utilizar juegos educativos en clase?

103 respuestas

80

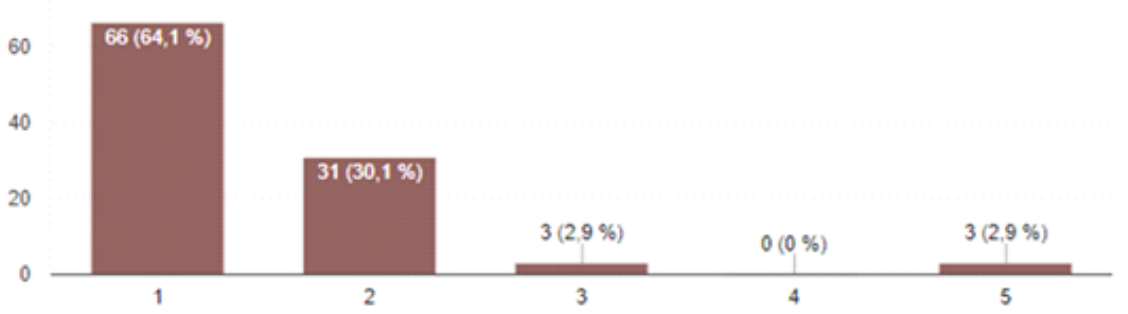

Ilustración no 3: Resultados encuesta de satisfacción del juego "Conceptúa". Las preguntas debían ser respondidas valorando de 1 a 5 , siendo 1 la mínima puntuación y 5 la máxima puntuación.

4. Formas de colaboración: Hacia una red nacional sobre "gamificación" en Derecho.

La "Ludoteca jurídica" pretende convertirse en una plataforma digital que sirva como "banco de materiales didácticos" en materia de "gamificación" en Derecho. De este modo, los profesores interesados podrán remitir juegos que hayan creado, siguiendo ciertas normas de estilo, y que, tras su revisión, serán maquetados para aparecer en la página web, con su pertinente ficha y encuesta de valoración. Se trata de una forma de colaborar con la creación de materiales, particularmente juegos educativos, para que sean utilizados por otros docentes en otras Universidades.

Actualmente, la plataforma digital establece diversas formas de colaboración para fomentar la "gamificación" en las disciplinas jurídicas. Si se trata de un docente universitario de alguna disciplina jurídica, creativo e innovador, la plataforma le anima a crear - o adaptar - tu propio juego educativo. Para ello, debe acceder a la pestaña "colabora" de la "Ludoteca jurídica" 40 y elegir la forma de colaboración:

40 Disponible en el siguiente enlace web: https://ludotecajuridica.es/colabora/ [Fecha de consulta: 15/09/2019]. 
1. Colaboración individual: El docente de forma individual, siguiendo los pasos disponibles en la página web, podrá remitir su juego (o juegos) para su revisión, aceptación y publicación en la plataforma digital.

También es posible colaborar de forma colectiva a través de proyectos de innovación docente.

2. Colaboración con proyecto de innovación docente (intrauniversitario): El docente puede solicitar un proyecto de innovación docente (o de materiales didácticos) en su Universidad sobre "gamificación en Derecho", contando con compañeros/as de su Facultad y publicar los resultados —o parte de ellos — en la plataforma educativa.

3. Colaboración con proyecto de innovación docente (interuniversitario): El docente puede solicitar un proyecto de innovación docente (o de materiales didácticos) en su Universidad sobre "gamificación en Derecho", contando con compañeros/as de su Facultad y miembros del equipo de la "Ludoteca jurídica", publicando los resultados —o parte de ellos - en nuestra plataforma educativa. De esta forma, se fomenta la colaboración y la innovación docente entre Universidades. En tal caso, el equipo de la "Ludoteca jurídica" estará a disposición — prestando ayuda y consejos - de los docentes para solicitar un proyecto de carácter interuniversitario.

Las últimas formas de colaboración persiguen crear una "Red nacional de proyectos sobre gamificación del Derecho". Ya se colabore de forma individual o colectiva, los docentes que participen aparecen en la página web como profesores colaboradores. De tratarse de colaboración colectiva, aparecerá asimismo un listado de los proyectos desarrollados en materia de "gamificación". La revolución de los juegos ha llegado a Derecho, debiendo observar su efectividad en la educación superior.

\section{Fomento de la educación 3.0 en Derecho.}

La "Ludoteca jurídica" no se olvida de la importancia de la Educación 3.0, es decir, de las herramientas y recursos educativos que ponen a nuestra disposición las nuevas tecnologías de la información y la comunicación (TIC). El sistema educativo no debe ser indiferente a estos avances tecnológicos. Hoy día, comienza a hablarse de la "Educación 3.0" como un "nuevo modelo educativo" basado en la incorporación de las herramientas y recursos digitales a las aulas. A diferencia del sistema tradicional, este nuevo modelo de aprendizaje resulta "más interactivo, participativo y creativo" para el alumnado ${ }^{41}$.

Somos conscientes de las ventajas que ofrecen las TIC. Por ello, la "Ludoteca jurídica" promueve el uso de los recursos digitales educativos en la enseñanza de disciplinas jurídicas. Por esta razón, en la pestaña "Contenido" de la plataforma digital se facilita información sobre algunas de las herramientas digitales que pueden aplicarse para enseñar Derecho. Actualmente, la página web facilita información y acceso directo a ciertos recursos digitales, como "Kahoot!", "Socrative", "Quizziz" o "Plickers" ${ }^{42}$. No obstante, con el tiempo se irán incorporando otros recursos relacionados con la educación

\footnotetext{
41 Así lo señala la plataforma digital REDEM. Red Educativa Mundial. (2017), en el artículo titulado "Educación 3.0: Usos de las redes sociales en el aula. Ventajas y desventajas". [Recurso en línea] https://www.redem.org/educacion-3-0-usos-de-las-redes-sociales-en-el-aula-ventajas-y-desventajas/ [fecha de consulta: 29/11/2019].

${ }^{42}$ https://ludotecajuridica.es/categoria/educacion-3-0/ [Fecha de consulta: 29/11/2019].
} 
3.0. Tales herramientas digitales permiten al docente elaborar cuestionarios de evaluación para que los alumnos, a través de Internet y el uso de sus dispositivos electrónicos tablets, teléfonos móviles, portátiles, etc.- o incluso mediante tarjetas con código QR, puedan realizarlos de forma instantánea, al tiempo que aprenden una materia jurídica con entretenimiento. Dada su operatividad, pueden aplicarse en diferentes contextos educativos. En particular, se pueden utilizar para evaluar o repasar conocimientos, realizar feedbacks tras impartir una clase — jornada, seminario, taller o curso - para observar el grado de comprensión e, incluso, como herramientas para crear o realizar algún juego educativo (así se puede observar en el juego educativo titulado "Gametest" de la Prof. ${ }^{\text {a }}$ María Luisa Roca).

Cada vez más docentes se muestran partidarios de emplear estas herramientas digitales en las aulas de Derecho, pues son evidentes los beneficios que su uso reporta (entre otras ventajas, aumenta la atención del alumnado, mejora el aprendizaje y potencia la motivación por la asignatura ${ }^{43}$. De hecho, se convierten en herramientas eficaces para valorar el grado de comprensión y atención del alumnado, para evaluar sus conocimientos, favorecer la autonomía y participación de los estudiantes, cambiar el proceso habitual de enseñanza-aprendizaje, ampliar las destrezas y las competencias tecnológicas, etc. Si bien, la educación 3.0 debe ser un complemento de las clases, nunca un sustituto. Aun así, debemos ser conscientes de la entrada del "mundo digital" en las aulas de Derecho.
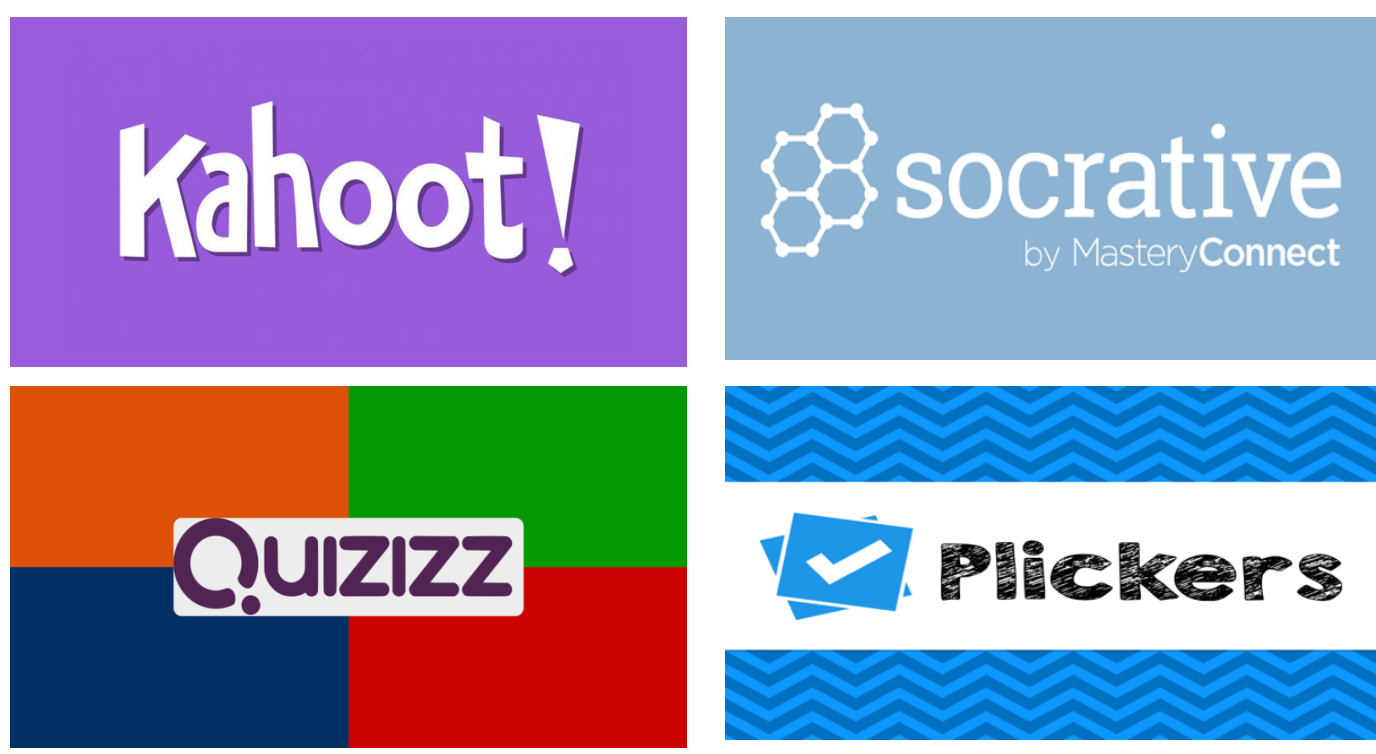

Ilustración $\mathrm{n}^{\mathrm{o}}$ 4: Plataformas para educación 3.0.

\footnotetext{
${ }^{43}$ Es tal la importancia que el uso de estos recursos digitales está adquiriendo en la Enseñanza Superior que, hoy día, no es raro encontrar trabajos sobre la incorporación de estas herramientas en asignaturas jurídicas. Así, pueden verse, entre otros: MARTÍN CARABALLO, A. M., HERRANZ PEINADO, P. y SEGOVIA GONZÁLEZ, M. M. (2017), "Gamificación en la educación, una aplicación práctica con la plataforma Kahoot", Anales de ASEPUMA, No 25, disponible en acceso abierto en www.dialnet.unirioja.es; y CARRIZOSA, E. (2017), "Introducción de la gamificación en la docencia. Cuestionarios interactivos con Kahoot”, en DELGADO GARCÍA, A. M. a y BELTRÁN DE HEREDIA RUIZ, I.: Las TIC y las buenas prácticas en la docencia del Derecho. Barcelona: Huygens Editorial.
} 


\section{Presente y futuro de la Ludoteca jurídica.}

Pese a que se trata de un proyecto educativo reciente, la plataforma digital "Ludoteca jurídica" ofrece actualmente diversos recursos educativos. En primer lugar, como hemos indicado anteriormente, pone a disposición de los docentes diversas fichas ilustrativas de juegos educativos que pueden aplicarse en clase para enseñar Derecho. Hasta el momento, se han publicado quince juegos sobre distintas disciplinas jurídicas $-\mathrm{o}$, en su caso, de carácter interdisciplinar-; y, en los próximos meses, se irán incorporando otros nuevos ${ }^{44}$, remitidos por docentes de diversas universidades. En segundo lugar, la "Ludoteca jurídica" cuenta con una pestaña sobre "Exámenes tipo test", a través de la cual tanto profesores como alumnos pueden acceder a cuestionarios sobre distintas materias jurídicas. El objetivo es crear un banco de cuestionarios-test sobre materias de diversas disciplinas jurídicas (Derecho Civil, Derecho Mercantil, Derecho Procesal, Derecho Administrativo y Derecho Financiero y Tributario). A la fecha de finalización de este trabajo, se encuentran ya disponibles diversos cuestionarios sobre Derecho Civil ${ }^{45}$; y, de forma paulatina, se irán publicando otros cuestionarios sobre otras materias y/o disciplinas jurídicas. Estos cuestionarios pueden utilizarse por profesores y alumnos. El docente puede usarlo como actividad a desarrollar en clase o como una tarea complementaria a realizar en casa. En tercer lugar, el profesorado puede conocer recursos digitales a través de la pestaña "Educación 3.0", con la finalidad de acercar el mundo digital a las aulas de Derecho. Y, por último, la "Ludoteca jurídica" también dispone de una pestaña sobre "Publicaciones", en la que se puede encontrar un "Blog" — en el que se publica información sobre la plataforma digital, la gamificación y la innovación docente— 46 , y otro apartado sobre publicaciones de "Actividades" — para informar sobre las actividades realizadas con el alumnado, y la presentación de la "Ludoteca jurídica" en congresos y seminarios -47 .

Dada la reciente publicación de la plataforma online —el 13 de mayo de 2019—, el contenido presente irá aumentando en el futuro y, asimismo, se irán añadiendo nuevas pestañas con fines educativos. En este sentido, cabe señalar que la "Ludoteca jurídica" recogerá una pestaña titulada "Aula práctica", en la que se publicarán casos prácticos de distintas disciplinas jurídicas. Si bien, las oportunidades en el ámbito educativo son infinitas, por lo que será el tiempo, así como la labor, compromiso y creatividad del profesorado colaborador, los elementos que marquen el desarrollo futuro de la plataforma digital.

Por el momento, la acogida por el profesorado ha sido bastante positiva. Actualmente, la "Ludoteca jurídica" cuenta con más de sesenta profesores colaboradores, de distintas universidades españolas y disciplinas jurídicas, que colaboran en la elaboración de los referidos cuestionarios tipo test. Asimismo, diversos docentes ya han manifestado su interés en solicitar un proyecto de innovación docente sobre "gamificación" en sus respectivas Universidades, relacionado con la plataforma digital. Esto último será decisivo para la creación de una "red nacional de proyectos" sobre dicha metodología docente en el ámbito del Derecho. En la pestaña "Equipo" se mostrarán los profesores

\footnotetext{
${ }^{44}$ Sobre los juegos educativos de la "Ludoteca jurídica", véase lo dispuesto en el apartado 3 de este trabajo.

${ }^{45}$ Disponibles en: https://ludotecajuridica.es/curso/derecho-civil/ [Fecha de consulta: 29/11/2019].

${ }^{46}$ Puede accederse al Blog a través del siguiente enlace: https://ludotecajuridica.es/categoria/blog/ [Fecha de consulta: 29/11/2019].

47 Las publicaciones sobre las "Actividades" se encuentran en el siguiente enlace: https://ludotecajuridica.es/categoria/actividades/ [Fecha de consulta: 29/11/2019].
} 
colaboradores y, además, los proyectos de innovación docente o de materiales didácticos relacionados con la plataforma digital.

Dicho lo anterior, y para concluir, indicar que ciertamente la "gamificación" es una metodología docente de escaso uso en las aulas universitarias de Derecho. Existen pocos estudios exhaustivos sobre el empleo de dicha técnica de enseñanza en el ámbito de las ciencias jurídicas — ventajas, inconvenientes, formas de instauración, etc.- . La "Ludoteca jurídica" es una plataforma digital que nace como "experimento educativo", con la finalidad de crear un entorno online que fomente la "ludificación" en clases de Derecho. Será, pues, el tiempo y su aplicación por el profesorado quienes nos muestren sus posibles beneficios y/o desventajas, la llegada de nuevas experiencias educativas complementarias e, incluso, su instauración como técnica de aprendizaje común. Si bien, lo más relevante es que constituye la "chispa" capaz de encender la creatividad de los docentes, así como la motivación y actitud de los estudiantes; y, en consecuencia, una fórmula innovadora distinta para la enseñanza del Derecho. No olvidemos, como señalaba Albert Einstein en una frase célebre, que "el juego es la forma más elevada de la investigación". Siendo así, puede que sea el momento de potenciar el rol de "gamificadores".

\section{Bibliografía.}

- ALEJALDRE DIEL, L. y GARCÍA JIMÉNEZ, A. M. . . (2015), “Gamificar: el uso de los elementos del juego en la enseñanza del español", en Congreso La cultura hispánica: de sus orígenes al siglo XXI. Publicaciones de la Asociación Europea de Profesores de Español. (En línea)

https://cvc.cervantes.es/ensenanza/biblioteca_ele/aepe/congreso_50.htm.

- BARBOSA GONZÁLEZ, A., RAPOSO RIVAS, M. y MARTÍNEZ FIGUEIRA, E. (2018). "Recursos para analizar el diseño y puesta en práctica de la gamificación en el aula”, en LÓPEZ-MENESES, E., COBOS-SANCHIZ, D., MARTÍN-PADILLA, A., MOLINA-GARCÍA, L. y JAÉN-MARTÍNEZ, A.: Experiencias pedagógicas e innovación educativa: Aportaciones desde la praxis docente e investigadora. Barcelona: Octaedro, págs. 843-852.

- BORRÁS GENÉ, O. (2015), Fundamentos de la gamificación. Madrid: Gabinete de Tele-Educación de la Universidad Politécnica de Madrid.

- CARRIZOSA, E. (2017), "Introducción de la gamificación en la docencia. Cuestionarios interactivos con Kahoot", en DELGADO GARCÍA, A. M. ${ }^{\mathrm{a}} \mathrm{y}$ BELTRÁN DE HEREDIA RUIZ, I.: Las TIC y las buenas prácticas en la docencia del Derecho. Barcelona: Huygens Editorial.

- CONTRERAS ESPINOSA, R. S. (2016), "Elementos de juego y motivación: reflexiones entorno a una experiencia que utiliza gamificación en una asignatura de grado para game designers", en CONTRERAS, R. S. y EGUIA, J. L.: Gamificación en aulas universitarias. Bellaterra: Institut de la Comunicació, Universitat Autònoma de Barcelona. 
- CONTRERAS ESPINOSA, R. S. y EGUIA, J. L. (2016), "Gamificación en aulas universitarias", en CONTRERAS, R. S. y EGUIA, J. L.: Gamificación en aulas universitarias. Bellaterra: Institut de la Comuninicació, Universitat Autònoma de Barcelona.

- GARCÍA JIMÉNEZ, A. (2017), "Serious games y gamificación, ¿en qué se diferencian?", entrada publicada en El Blog de Gestazión; disponible en https://blog.gestazion.com/.

- GÓMEZ GARCÍA, I. (2015), “Gamificación como recurso de la ingeniería en comunicación social”, Revista 'Razón y Palabra', No 90.

- GONZÁlez GONZÁleZ, C. S. y MORA CARREÑO, A. (2014). "Propuesta metodológica de gamificación en la enseñanza técnica superior", en Actas del XVI Simposio Internacional de Informática Educativa (SIIE' 14): Acceso masivo y universal para un aprendizaje a lo largo de la vida. Logroño: UNIR-Universidad Internacional de La Rioja.

- GUTIÉRREZ-ARTACHO, J. y OLVERA LOBO, M. D. (2017). “Gamificación para la adquisición de competencias en la educación superior: el caso de la traducción e interpretación", en PADILLA CASTILLO, G.: Aulas virtuales, fórmulas y prácticas. Madrid: McGraw Hill.

- GRAU, J. (2016), "La diferencia entre gamificación y serious game”, entrada publicada en www.beprimsa.com.

- HUNTER, D. y WERBACH, K. (2014), Gamificación. Revoluciona tu negocio con las técnicas de los juegos. Madrid: Perarson.

- LÓPEZ LAGO, N. (2016), “Cómo aplicar la gamificación o ludificación educativa en el aula", en el Blog CEAC del Grupo Planeta Formación y Universidades; disponible en www.ceac.es/blog/.

- LOZADA ÁVILA, C. y BETANCUR GÓMEZ, S. (2017). "La gamificación en la educación superior: una revisión sistemática", Revista Ingenierías Universidad de Medellín, vol. 16, № 31 págs. 97-124.

- MARTÍN CARABALlO, A. M., HERRANZ PEINADO, P. y SEGOVIA GONZÁLEZ, M. M. (2017), "Gamificación en la educación, una aplicación práctica con la plataforma Kahoot", Anales de ASEPUMA, No 25.

- RODRÍGUEZ, F. y SANTIAGO, R. (2015), Gamificación: cómo motivar a tu alumnado y mejorar el clima en el aula. Madrid: Digital-Text. Grupo Océano.

- RUDA GONZÁLEZ, A. y YOLDI ALTAMIRANO, C. (2014). “Aprender jugando. Experiencias de aprendizaje mediante juegos en la Facultad de Derecho de la UdG", Revista CIDUI, $\mathrm{N}^{\mathrm{o}} 2$. 
- SÁNCHEZ APARICIO, J. C. (2016), “Gamificación, gamification, ludificación... ¿cómo me llamo?”, entrada publicada en el blog ‘El diario de Snackson'; disponible en www.snackson.com.

- TEIXES, F. (2014), Gamificación: Fundamentos y aplicaciones. Barcelona: UOC Business School. 